\title{
El recuerdo en las historias de vida
}

\author{
Ma. Gracia Castillo Ramírez \\ INAH-JALISCO
}

\begin{abstract}
El recuerdo en los testimonios, producto de las entrevistas de historia oral, se manifiesta de diferentes maneras; en la memoria de los sujetos inciden factores tales como el relato de un testimonio temático o de una historia de vida, de un acontecimiento reciente o remoto, de la posición social y de características personales del informante.
\end{abstract}

\begin{abstract}
A nte la escasez de datos acerca de la vida cotidiana, los historiadores interesados en explicaciones que completaran la perspectiva de las visiones existentes, se enfrentaron al reto de leer e interpretar los documentos tradicionales de una manera diferente, o bien de encontrar y construir un nuevo tipo de fuentes. La historia oral, como método auxiliar de la investigación social, rescata testimonios acerca de la forma particular en que diversos individuos participaron, vivieron, sintieron y comprendieron determinados acontecimientos o procesos y, a partir del relato de
\end{abstract}

cada uno de ellos, construye fuentes documentales que hagan posible una reconstrucción histórica menos parcial y una visión más completa del acontecer social.

En los relatos testimoniales los recuerdos del individuo se tornan útiles para la mejor recreación del pasado. La narración vívida del entrevistado rescata el sentido que la persona dio a los hechos que observó o en que participó, aspecto del que difícilmente podríamos darnos cuenta si sólo recurrimos a documentos de carácter oficial.

El relato de cada informante pone de manifiesto, de manera especial- 
mente vívida, la colectividad existe gracias a la interacción de individuos comunes, cada uno de los cuales ocupa un sitio y desempeña actividades específicas, que si bien tienen similitudes con las de otros, también son diferentes a ellas. Además de una historia propiamente dicha, los testimonios orales constituyen fuentes para estudios más amplios en los que, al entrelazar la manera en que diversos individuos han vivido etapas o acontecimientos de la historia, se puede obtener una visión más global de lo rico y multifacético de la vida del hombre en sociedad, de la vida cotidiana de grandes sectores de la población, de la memoria colectiva.

A través de la participación en el Programa de Historia Oral del Centro INAH Jalisco, al realizar, procesar, editar y utilizar como fuente entrevistas, he observado que el recuerdo del informante es variable -tanto cuantitativa como cualitativamente-, y depende no sólo de un testimonio temático o de una historia de vida, de un acontecimiento reciente o remoto, sino también de su posición social y sus características personales.

Si partimos de la consideración de que los testimonios orales, al mostrarnos la riqueza y versatilidad de una vida, nos hacen conscientes del papel que cada uno desempeñamos en la historia y nos dan una perspectiva diferente de la estructura y del funcionamiento de la sociedad, este trabajo se propone someter a discusión algunas reflexiones en torno a algunos factores que pueden incidir en la memoria individual y en cómo la historia oral rescata y complementa la memoria colectiva.
$\mathrm{Al}$ acercarse el historiador oral por primera vez a un posible informante, lo hace con una idea clara de que le puede proporcionar datos -principalmente cualitativos-, respecto a un proceso o acontecimiento histórico específico y generalmente así se lo hace saber.

Mas allá de la emoción que al entrevistado le cause el que se reconozca su participación en tal o cual movimiento o que su vida resulta importante y significativa para el conocimiento de lo social, este primer contacto provoca en él reacciones tales como la rememoración, la reflexión de sus propias experiencias y de la importancia del aspecto en cuestión así como la preocupación por la forma en que habrá de comunicarlo.

Lola Vidrio, una entrevistada, comentaba: "es muy curioso, porque a propósito de estas conversaciones con usted, yo me he puesto a pensar, ¿por qué?, ¿cómo es que una persona de la familia cambia su manera de pensar o va encontrando su rumbo y los demás no?" Y continúa analizando y reflexionando sobre cómo, de ser una amante de la literatura se convirtió en militante política. ${ }^{1}$

Dicho de otra manera, la entrevista induce un proceso de investigación al interior del propio informante, en cierta manera similar a lo que ocurre en la labor del historiador. Empieza

\footnotetext{
${ }^{1}$ Entrevista a la señora Dolores Vidrio Beltrán, realizada por Julia Tuñón, los días 29 y 31 de mayo, 16 de junio, 7,13 y 20 de septiembre, $10,11,13,16$ y 31 de octubre, 1,13 y 15 de noviembre y 4 de diciembre de 1978 , en la ciudad de Guadalajara, Jalisco.
} 
con la fase de recolección de información, hace un gran esfuerzo por recordar detalladamente todas y cada una de las experiencias propias, las de sus compañeros y contemporáneos, y en general de las características del tiempo sobre el que hablará. La preocupación por la veracidad, exactitud o credibilidad del propio testimonio se manifiesta frecuentemente. Un caso ilustrativo es la misma entrevista de Lola Vidrio, la cual en diversas ocasiones hizo referencia a su proceso de rememoración: "No me acuerdo, yo creo que...". "Entonces yo me acordé también de un detalle... yo recuerdo muy bien...". "Pues no, no me acuerdo muy bien, necesitaría sacar cuentas, debe haber sido, yo creo que entré a los 17 años a trabajar, nací en siete, más 17, serían $24 . . . "$. Y en el siguiente párrafo: "Esa temporada fue muy rara, yo me... no me puedo, pues no puedo coordinar bien mis ideas para saber, de dónde de aquella chamaca que fui..." "pero no me acuerdo si todavía no trabajaba yo, se... se me confunde el tiempo".2

En ocasiones los entrevistados incluso revisan sus documentos y recurren a lecturas periodísticas o históricas para aclararse confusiones de fechas o personajes.

Al igual que el investigador, el testimoniante selecciona, clasifica y cataloga su información; privilegia algunos datos y desecha otros. No es raro que en las diferentes sesiones se nos reciba con un legajo de documentos, recortes de periódico, fotografías o libros

${ }^{2}$ Ibid.

EL RECUERDO EN LAS HISTORIAS DE VIDA que el informante considera que nos pueden servir.

En ocasiones, dependiendo de su conciencia histórica social, también hace una interpretación o valoración social de su experiencia, de acuerdo con las concepciones que respecto al tema se tuvieron en el periodo en que ocurrió o en el momento del interrogatorio. Continuando con Lola: "Y todo eso se pasó en una forma tan rápida que casi ni se siente, pero sí veo yo ahora..., una de las consecuencias de la revolución fue haber cambiado en ciudades del tipo de Guadalajara, del centro de la república, las costumbres tan hipócritas, porque no eran más que hipocresías, las monerías de la gente de aquí, y empezaron a... hacerse pues, más fiestas, más liberal la vida." 3

Además, en el entrevistado se hace presente la preocupación por cómo comunicar, cómo narrar lo vivido. En este sentido, casi para terminar su entrevista, Joaquín Vázquez asegura: "Yo en lo que voy a escribir tengo que poner muchas cosas, desde cuándo comencé y por qué comencé." ${ }^{\prime}$

La rememoración del informante se enfrenta, en ocasión de la entrevista, a la forma en que se le va cuestionando, al esquema que respecto al problema tiene elaborado el historiador oral. Éste busca, ante todo, datos no recuperables a través de las fuentes tradicionales, a la vez que indagar cómo

\footnotetext{
${ }^{3}$ Ibid.

${ }^{4}$ Entrevista al señor Joaquín Vázquez, realizada por Jesús Gómez Fregoso, el día 12 de junio de 1977, en la ciudad de Guadalajara, Jalisco.
} 


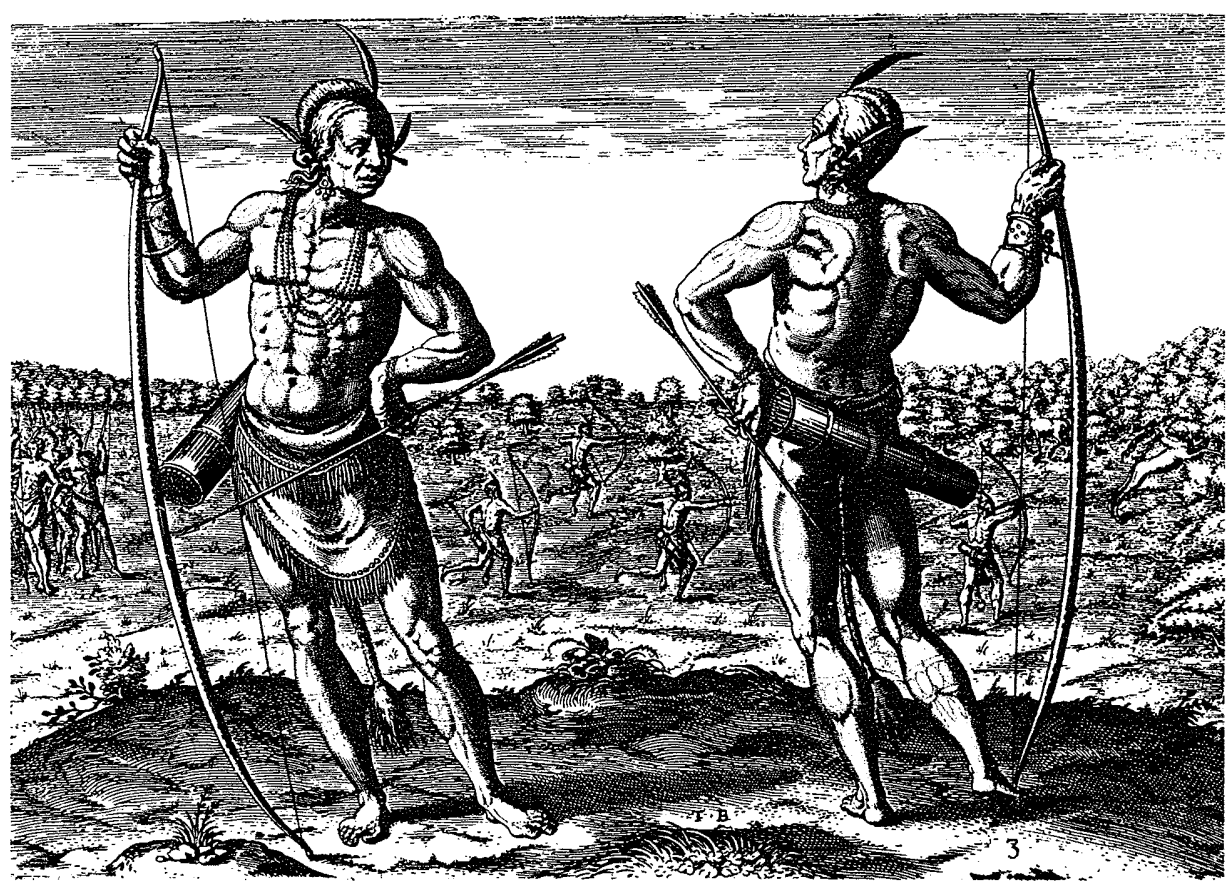

vivió, sintió, interpretó, asimiló y se identificó el entrevistado con los acontecimientos y qué significaron y significan para él. El interrogatorio en muchos casos ayuda a organizar, mejorar o reinterpretar el recuerdo, pero en otros lo confunde y provoca la duda.

Estos aspectos que se viven de manera general en las entrevistas, tienen variaciones individuales y también entre ciertos grupos. Más allá de la facilidad o dificultad de expresión, de la formación académica o nivel de conocimientos, la evocación de la memoria por parte del individuo, el manejo que se hace de ella, los significados que se le dan y la forma de narrarla en la entrevista, están influidos tanto por la situación económica, política, social y afectiva del informante, como por la forma en que son desencadenados.

En las pocas entrevistas temáticas con que cuenta el acervo de Historia Oral del INAH en Jalisco, se observan dos constantes: una de ellas es la tendencia del individuo a hablar de manera impersonal, como si buscara difuminarse en los procesos y renunciar a su papel protagónico en la entrevista; narra un recuerdo que parece oscilar entre el suyo propio y el del grupo. La otra constante es una propensión a brindar, como propios, datos que no son fruto de su experiencia personal sino de lecturas, aspecto que queda al descubierto cuando se plantean pre- 
guntas como: "Y ¿usted qué hizo? ¿con quién estaba? -No, yo no estaba allí, eso yo lo leí."

Cuando el interrogatorio propicia un repaso de la existencia del sujeto privilegiando ciertos aspectos, es decir, tiende a hacer una historia de vida, la información resultante difiere cualitativamente de la que se obtiene cuando sólo se refiere a temas determinados. En este sentido, resulta significativo lo que me pasó con don Esteban Cuevas Villanueva, anciano al que contacté por su participación en el movimiento obrero de los años veinte, cosa que le hice saber en la cita preliminar a las grabaciones en la cual estuvimos platicando sobre el tema sin contextuarlo en el trascurso de su vida. En esa ocasión él se proclamó socialista rehusándose a hacer más aclaraciones al respecto. Después de tres sesiones en las que me fui adentrando en su vida personal y evidenciando sus riquezas y limitaciones a través del interrogatorio, no tuvo mayor empacho en responder a la pregunta sobre qué era ser socialista: "¿Socialista?, pues tenía la tendencia de reunir a todos los que iban ahí, con esa, con la tendencia de, socializarse, relacionándose uno con otro y con otro...". 5

Otro ejemplo de los mayores frutos que se pueden obtener cuando la entrevista se enfoca a rescatar la historia de vida, así como de las variantes grupales en cuanto al manejo de la me-

\footnotetext{
${ }^{5}$ Entrevista al señor Esteban Cuevas Villanueva, realizada por Ma. Gracia Castillo Ramírez, los días $18,20,25,27$ y 31 de marzo, 1, 9 y 13 de mayo de 1980 , en la ciudad de Guadalajara, Jalisco.
}

moria, fue la actitud de tres empresarios ante la experiencia de la historia oral. En principio mostraron resistencias y a ninguno de ellos le importó detallar el relato de su actividad económica. En tanto que don Augusto, el más joven, al terminar la segunda sesión manifestó de plano que no tenía tiempo, ni afecto por la historia; los otros dos, don Juan, un emigrado español, y don Eduardo, hombre con cierto ascendiente y participación en la sociedad tapatía, mostraron más atracción por la experiencia de la entrevista en la medida en que se les hacía recordar y se mostraba interés por diversos aspectos de su vida personal individual.

A diferencia de los casos anteriores, don Gilberto, universitario ilustrado que había desempeñado cargos importantes en el gobierno del estado, acostumbrado a lidiar con los reporteros y a dictar conferencias, aceptó de buena gana el ser entrevistado; sin embargo, cuando empecé a preguntarle por sus padres y su infancia, con la grabadora funcionando, el hombre empezó a temblar y a responder con lenguaje poético; a los 25 minutos me pidió que apagara la grabadora, dijo que me contaba lo que yo quisiera pero sin la grabadora. Tres veces volví a desayunar en su casa platicando de aspectos personales, pero nunca volvió a acceder a grabar. Ante lo ocurrido me surgió la interrogante: ¿no hubiera sido mejor hacerle a don Gilberto una entrevista temática?

A pesar de que las experiencias en ambos sentidos muestran la conveniencia de programar el tipo de entrevista tomando en cuenta las caracterís- 
ticas personales y actividades públicas de los informantes, por lo que se refiere específicamente al recuerdo y a su narración, me inclino a considerar que éstos son cualitativamente mejores cuando el historiador oral se orienta a reconstruir la historia de vida, pues de esa manera no sólo se estimula la memoria, sino que además se proporciona confianza al informante para que reduzca las censuras que se autoimpone. Lola Vidrio, ya avanzada la entrevista comentaba: "bueno... eso sí lo puedo decir; con todas las enormes virtudes que él tuvo y que acompañaron toda su vida, era como la gente de su tiempo... (risa), admirador de la paz de Porfirio Díaz". Por su parte, Josefina Ortiz Mariotte, después de preguntar si no sería conveniente apagar la grabadora para comentar algo, al simple "yo creo que no" de respuesta por parte del entrevistador, siguió hablando. ${ }^{6}$

De manera similar a la forma en que la técnica utilizada en la entrevista puede estimular la memoria del informante, los testimonios orales pueden, y de hecho lo hacen, reestructurar la memoria social. Al dar voz al hombre común, la historia oral cuestiona la objetividad de las verdades institucionales. Las interpretaciones y significados que los informantes dan a las políticas, procesos o acontecimientos que les tocó vivir, frecuentemente no coin-

\footnotetext{
${ }^{6}$ Entrevista a la profesora Josefina Ortiz Mariotte viuda de Rivera, realizada por Agustín Vaca García, los días 16, 19, 21, 23, 27 de enero; $1,5,7,12,14,17,24,26$ de marzo; 16 , $18,21,23,25,28$ de abril; $2,6,8,12,14$ de mayo de 1980 , en la ciudad de Guadalajara, Jalisco.
}

ciden del todo con las versiones oficiales y las académicas basadas en fuentes y métodos tradicionales.

En las entrevistas de historia oral, la subjetividad del informante -por más discutida o cuestionada que esté-, proporciona una visión "espontánea" y "sincera" de los hechos, que poco tiene que ver con intereses políticos y mucho con la multifacética realidad histórica. Es por ello que las versiones de los entrevistados posibilitan el acercamiento a la comprensión de la pluralidad de representaciones y significados que un mismo proceso o acontecimiento puede tener para los diversos grupos, sectores o individuos que conforman la sociedad. Dichas representaciones y significados se hacen patentes no sólo en lo narrado, sino también en la forma en que lo expresan, en lo que recuerdan de sus vivencias y también en lo que olvidan.

La versatilidad de los testimonios rescatados a través del método de la historia oral permite confrontar las coincidencias y las divergencias entre el contexto general y las particularidades individuales. Lo narrado en las entrevistas contribuye a rescatar aspectos de la realidad a los que difícilmente podemos acceder por otros medios. Un ejemplo en este sentido se refiere al enfrentamiento entre la Iglesia y el Estado durante las décadas de 1920 y 1930. En esa pugna de poder, las dos instituciones se disputaron el control de los maestros, cuya labor era reconocida como pieza clave en el funcionamiento de la sociedad y, con miras a conservar cohercitivamente la fidelidad de los docentes, adoptaron disposiciones que afectaban al común de 
la población, en particular el derecho "universal" de los niños a la educación. La historia tradicional menciona las sanciones -cese o excomuniónque por parte de ambos bandos se establecieron en Jalisco para los mentores que no acataran sus disposiciones, incluso puede dar cuenta de los que fueron suspendidos; sin embargo difícilmente puede transmitir qué fue lo que sintieron y pensaron los mexicanos afectados en sus creencias o en su trabajo por esas disposiciones, y menos aún, la forma que cada quien encontró para hacer frente al conflicto derivado de la disyuntiva en que los colocaron las instituciones citadas. Wilebalda Rodríguez, a través de su testimonio, nos comparte las angustias que tal situación provocó en ella y en su familia, los razonamientos en torno a cómo resolvió personalmente el dilema en que la situaba ese enfrentamiento que no sintió como suyo a pesar de ser católica. Para ella quedaba claro que como maestra tenía la obligación de transmitir valores y normas morales generales y que la enseñanza de la religión era algo que tocaba a los padres de familia; asimismo, estaba convencida de la necesidad que los niños tenían de la escuela. Además, como católica, su relato la hace aparecer con una espiritualidad profunda, pero práctica. Para impedir, en la medida de sus posibilidades, que los menores quedaran sin instrucción, la estrategia que elaboró fue la de acatar las disposiciones oficiales y eludir la excomunión regresando a Colotlán, población que eclesiásticamente estaba sujeta a la diócesis de Zacatecas, donde dicho castigo religioso no existía. "Yo pensé en protegerme, porque ipor qué le quitan a uno la manera honrada de ganar su pan, si no vamos a hacer cosas malas contra nadie? No justificaba yo eso."

En cuanto a las interpretaciones que se alejan de las sostenidas por los organismos que detentan el poder, incluso encontramos visiones diferentes entre personas que vivieron situaciones similares, que desmitifican y amplían la visión impuesta por la "historia patria". Desde esta perspectiva se ha dado un papel importante en el siglo Xx a la llamada educación socialista, la cual fue utilizada por el proyecto cardenista de consolidación nacional como uno de los medios para lograr el control de las masas, ya que a través de ella se mostraba, entre otras cosas, la preocupación del gobierno por la educación popular. Testimonios rescatados con el método de la historia oral nos muestran otros puntos de vista del proceso. Irene Robledo, maestra citadina, señala que la llamada "educación socialista" propuso reformas interesantes encaminadas fundamentalmente a mejorar la educación y las condiciones de vida en el campo; ${ }^{8}$ en cambio, testimonios de maestras rurales como Wilebalda Rodríguez Jiménez o Josefina Ortiz Mariotte apuntan a que, a pesar de la gran alharaca en torno a dicho proyecto pedagógico,

\footnotetext{
${ }^{7}$ Entrevista a la profesora Wilebalda Rodríguez, realizada por Julia Tuñón, los días 4, 5, 6, 10 y 11 de enero de 1977 , en la ciudad de Guadalajara, Jalisco.

${ }^{8}$ Entrevista a la señorita Irene Robledo García, realizada por Julia Tunón, los días 9, 20, 22 y 27 de julio; 3 y 10 de agosto de 1976, en la ciudad de Guadalajara, Jalisco.
} 
nunca se especificó concretamente en qué consistía o cuáles eran sus premisas pedagógicas, simplemente se les pidió que establecieran la enseñanza de cuestiones prácticas y se abstuvieran de impartir instrucción religiosa, cosa que ya por iniciativa personal, ya porque el ambiente se los exigía, o por ambas situaciones, venían desarrollando desde antes. En el caso de Wilebalda, si la entrevistadora no hubiera insistido en la pregunta por la educación socialista, ella no hubiera comentado el tema. El ejemplo evidencia además cómo el recuerdo y las formas de comprender, interpretar y narrar, están vinculados con la situación sociopolítica del informante. Estas versiones diferentes también pueden explicarse por la posición social, cultural y política de cada una de las maestras citadas. En tanto que la señorita Robledo era alta funcionaria universitaria, no lo eran las otras dos. Wilebalda trabajó siempre en grupos de primaria y durante mucho tiempo en el medio rural; Josefina Ortiz Mariotte, a diferencia de ellas dos, fue madre de familia prácticamente sola, pues enviudó muy joven y tuvo que hacerse cargo de cuatro hijos y, además de su labor docente, participó en la fundación de las primeras organizaciones y sindicatos magisteriales. Curiosamente, las tres maestras apuntan que en general hubo un repudio hacia esta disposición porque el término socialista se asociaba con el comunismo, el cual, como proyecto social y como sistema de pensamiento, era hostigado por el Estado mexicano y la Iglesia.

Las características de la memoria, la forma de evocarla y narrarla -materia prima de los testimonios orales-, así como la capacidad de olvido y mentira de la gente, han sido los principales cuestionamientos a los que se ha enfrentado la historia oral. Otro argumento que se esgrime en contra, es el hecho de que la interpretación de la vida personal varía en momentos y situaciones diferentes, lo cual resulta comprensible, pues al igual que la historia, se va completando y entendiendo más a medida que se integra con otros conocimientos y con la vida misma.

Esta discusión, a la que desde cierto punto de vista se puede calificar de maniquea, se irá superando en la medida en que los historiadores orales muestren, con sus investigaciones, lo que el cuestionamiento del pasado desde el presente vivo, puede aportar a la comprensión de los procesos históricos. 